\title{
DOES THE COMPUTER PROGRAMMING STUDENT UNDERSTAND WHAT CONSTITUTES PLAGIARISM?
}

\author{
Jeanne M. Baugh, Robert Morris University, baugh@rmu.edu \\ Paul J. Kovacs, Robert Morris University, kovacs@rmu.edu \\ Gary A. Davis, Robert Morris University, davis@rmu.edu
}

\begin{abstract}
In this era of Internet access, faculty in higher education need to be proactive in preventing plagiarism in computer programming courses. But do students consider copying of computer code (either from another student or posted code on the Internet) as plagiarism? This paper investigates how the Computer Information Systems major views the copying of code, as well as other related cheating behaviors in the classroom. From the results of this research, it is clear that (although students report that they view copying of code as plagiarism), students do not view copying code as a serious offense. Course policies concerning copying of code from any source must be explicitly stated in the syllabus. In addition, faculty must provide guidance as to what is acceptable in terms of incorporating programming code from the Internet.
\end{abstract}

Keywords: Cheating in Programming Assignments, Plagiarism, Academic Integrity

\section{INTRODUCTION}

One of the authors of the current research has been teaching programming for twenty five years. An incident this past semester prompted some analysis of the rules of the author's programming courses. These "rules" are contained in the course syllabus. A final assignment of a Java course asked the students to create a computer game of their choice. A "red flag" was raised when one student turned in an exceptionally well-written Tic-Tac-Toe program. This student had actually been doing very poorly in the course up until this point. The probability that he was able to successfully write an events-driven, very complicated graphical program seemed quite slim. A search was made of the Internet for similar code. Amazingly, the very first search "hit" was exactly the same code turned in by the student. The only thing that was changed was that the student had deleted the comment statements; he did not even do a global change to variable names.

It seemed a clear cut case that the student had been guilty of plagiarism. As a result, the incident was turned over to the academic standards committee at the authors' institution. The student claimed that the code was open source, and therefore, it was okay for him to turn it in as his own work. Further, the committee felt that the code was not "exactly the same" (because of the deletion of the comment statements) and could not be considered plagiarism. This committee was comprised of faculty members from various departments on campus. After a great deal of discussion, the committee finally agreed that the student had plagiarized the programming code.

The same author also recently had six students turn in exactly the same code in a $\mathrm{C}++$ course. One student gave her code to another student to "review." In this instance, the other student went well beyond "reviewing" the code and apparently copied the code and then proceeded to forward it on to other students who, in turn, also copied the code.

Finally, a third blatant incident of unethical behavior occurred when a student advertised on Craig's List for someone to write his code for a large $\mathrm{C}++$ project. The post was as follows:

I have a $\mathrm{C}++$ project that needs done ASAP. It is broken down into four parts, the project is simple for someone who knows the coding well but I do not and do not feel like learning it because I have other classes to worry about. I will pay for each part of the project. Email me: xxx@xxx.edu. These assignments should only take 30 minutes to each part. EASY MONEY!! I can email you the assignments so we do not even have to meet until payment. 


\section{Issues in Information Systems}

Volume 13, Issue 2, pp. 138-145, 2012

The above post was upsetting on many levels. First, the advertising blatantly solicits cheating. Second, the advertisement brags that the assignment was easy and each phase would take only 30 minutes to complete!

After this event, this author began to examine what was happening. Why did the student think it was okay to post this? Why did the six students think that they could get away turning in the same exact C++ code? Why did the academic standards committee have such a hard time coming to the obvious conclusion that the student had plagiarized? The syllabus did say "Copying of code is considered cheating." But was the syllabus specific enough? Do the students really understand what cheating is? What needs to be changed so this does not happen in the future?

\section{CHEATING IN IS/IT/CIS PROGRAMS}

Plagiarism is the act of taking someone else's work and representing it as your own. In other words, this is considered cheating. Gregory Cizek author of the comprehensive book, "Cheating on Tests" says "Nearly every research report on cheating -- has concluded that cheating is rampant" [5].

Academic dishonesty has been a prevailing problem in America's colleges and universities. In a recent study, for example, researchers found that nearly two-thirds of undergraduate students admitted to cheating in their college courses [23]. The same authors concluded that cheating in college is not just pervasive but is also a "... growing phenomenon." Few researchers, however, have specifically examined cheating in Information Systems (IS) and Information Technology (IT) degree programs.

Some authors have concluded that students in Information Systems (IS), Information Technology (IT), and Computer Science (CS) programs not only cheat, but cheat at greater frequency than students enrolled in other degree programs [14]. Among reasons cited for the increased cheating in computing programs is the belief by students that software code is regarded in the same manner as the solution to a math problem (i.e., having one correct answer). Students writing computer programs may feel compelled to provide the "correct" answer rather than applying creative solutions to solve a problem scenario. Other reasons given for the increased cheating by IS/IT/CS students include the common practice by professors to re-use past programming assignments. The availability of past assignments encourages cheating because "functioning" programming code is available from former students [14]. Other authors blame the high levels of cheating on increased availability of online content. It is common practice (and convenient) for students to do "Google" searches for similar programs and plagiarize the software code [22]. Finally, the higher incidents of students cheating in computer disciplines may simply be attributed to the availability of better tools to detect cheating. Professor Lenny Pitt from the University of Illinois states, "Cheating has gone up across many fields because it's easier to find with the tools that we have today" [14].

The computer programmer's code of ethics endorsed by the Association for Computing Machinery (ACM) states the following: "Each computer programmer must recognize and note those who helped create any software applications he works on. If a programmer is going to use even just one line of another programmer's written computer code, the current programmer must note it both in the comments of the software application and in any user documentation the programmer might create" [12].

Some studies suggest that students in many introductory courses are cheating. At Stanford University, 23\% of their honor code violations involved introductory computer programming courses; while these computer science students make up only $6.5 \%$ of the student body.

At the University of Florida, 97 students were caught cheating on programs that were turned in as a final exam. The students were even warned that there were "markers" in the files and they could be easily caught cheating. Various penalties were issued based upon the willingness of the student to admit to cheating. [1]. 


\section{Issues in Information Systems}

Volume 13, Issue 2, pp. 138-145, 2012

As the Internet has grown, plagiarism has become more prevalent. There are many Internet locations where one may get guidance on cheating. For example, one location, [10] lists 40 different ways to cheat along with how-to videos and various warnings.

Today, there are web sites specifically intended to aid academic swindlers and how-to cheat books are routinely sold over the web. Michael Moorer's Cheating 101: The Benefits and Fundamentals of an Easy A is one of the most successful [15]. The New York Times, reported that Moorer, a middle-aged former journalism student, has sold tens of thousands of copies of his handy guide to academic larceny.

The CIS student is very computer savvy and therefore, well aware of the online resources that can aid in cheating. These resources not only cover the copying of code, but also using email, instant messaging, pagers, smart phones, etc., during an exam. The author used to allow the use of calculators during an exam. However, since cheating with Smart Phones is so prevalent, no digital devices of any kind are permitted during exams.

\section{THE HUMAN TENDENCY TO CHEAT}

Various reasons have been given as to why college students may consider cheating on examinations and assignments. In their study, authors Rettinger and Kramer [21] found support for "Neutralization Theory," as a reason why students may consider cheating. In Neutralization Theory, students are willing to cheat because they have found ways of "rationalizing" the cheating behavior. For example, students may blame their cheating on the performance of the instructor, the prevailing culture, or the behavior of fellow classmates [16]. Under this theory, students may rationalize their cheating behavior with excuses like "everyone else is doing it" [19].

Rettinger and Kramer also cite "Goal-Orientation Theory" as another possible explanation as to why students cheat [21]. Within Goal-Orientation Theory, students are either motivated by intrinsic or extrinsic factors. Intrinsic factors, for example, would include a student's desire to learn or master a particular concept. Extrinsic factors, by contrast, would include the student's desire to perform well or earn good grades [2,7]. In their study, Rettinger and Kramer affirmed that Intrinsic motivation (i.e., Mastery of a Subject) tends to invoke less cheating; whereas Extrinsic motivation (i.e., Recognition of Performance) tends to invoke more cheating [21].

This Extrinsic motivation may be a result of prevailing norms within our American culture. In his 2004 book, The Cheating Culture: Why More Americans Are Doing Wrong to Get Ahead, Callahan proposed that the current generation is under more pressure than past generations to perform well in order to be admitted to graduate or

\section{INTERNATIONAL STUDENTS}

professional schools and, ultimately, get a job [4]. Other researchers agree, "If winning is everything, then cheating simply becomes a tool to use in pursuit of this higher goal" [23].

Although many authors have focused on American students and American culture, some authors have explored the relationship between culture and cheating. In 2009 for example, Teixeira and Rocha conducted a study involving over 7,200 students enrolled in 42 universities located in 21 countries. The 2009 study revealed that there is great variability across countries and cultures regarding students' probability to cheat in college courses [24]. Specifically, the 2009 study revealed that the probability of cheating was lowest $(5 \%)$ in universities located in Scandinavian countries (Denmark and Sweden). By contrast, the same study revealed that the probability of cheating was highest (88\%) in Eastern European countries (Poland, Romania, and Slovenia). These data suggest that cultural differences from one country to the next may influence the likelihood of a student cheating in college. In her article, Marsan found that "Students often resort to cheating because they feel excessive pressure from their peers and their families to excel" [14]. In the same article, Professor Lenny Pitt noted, "Anecdotally, we see a larger incidence of cheating among foreign students then [sic] domestic students, and I think part of that is that they are under extreme pressure to do well and succeed ... even if that means taking shortcuts" [14]. 


\section{Issues in Information Systems}

Volume 13, Issue 2, pp. 138-145, 2012

\section{DO IS/IT/CIS STUDENTS UNDERSTAND PLAGIARISM?}

Because students have instant access to many resources when working on computer programming assignments, when is too much help from an outside source "over the line" and into the area of plagiarism? Do students really view the copying of code as cheating?

A survey of Computer Information Systems (CIS) majors was given to 115 Computer and Information Systems undergraduate students at a private University. Those completing the survey were at the following academic levels:

$\begin{array}{ll}\text { Freshman } & 19 \\ \text { Sophomore } & 29 \\ \text { Junior } & 31 \\ \text { Senior } & 21 \\ \text { Grad } & 15\end{array}$

Some of the questions (abbreviated) and yes/no percentages of responses can be found in the Appendix in Table 1: Student Questions and Responses.

This was an anonymous survey, so hopefully the students were honest with their responses. When studying the results in the table, some interesting findings are apparent. For example, of those surveyed, 52\% felt that copying of code from the Internet is "cheating," but only $30 \%$ of the students felt that the downloaded code needed to be cited. Students may feel that code on the Internet is "fair game" and using that code for an assignment is acceptable. While 78\% said they have searched the Internet for help on an assignment, only 17\% said they actually downloaded code for an assignment. This finding begs the question: did the students decide against plagiarizing code from the Internet or did they not find the code that they were looking for?

$59 \%$ of the students felt that the copying of code from another student is "cheating." But as all of us who teach programming know, this type of cheating is the type most often discovered. Additionally, $52 \%$ feel that copying of code from the Internet is cheating and 59\% feel copying of code from a fellow student is cheating. Students in the survey seemed to consider copying programming code from another student as being more malicious than downloading code from the Internet.

Additional findings from the survey: students reported working in groups for an individual assignment (39\%), giving code to another student (56\%), reviewing another student's code $(62 \%)$ and using a smart phone during an exam (17\%). These are all activities that could lead to cheating. A few students even admitted that they emailed or sent a text during an in-class examination. With this generation's digital technology skills, there most certainly will be more and more electronic ways to cheat in the future.

The authors' university requires a plagiarism statement in each syllabus. It is as follows:

Plagiarism, taking someone else's words or ideas and representing them as your own, is expressly prohibited. Good academic work must be based on honesty. The attempt of any student to present as his or her own work that which he or she has not produced is regarded by the faculty and administration as a serious offense. Student academic dishonesty includes but is not limited to:

- Copying the work on another during an examination or turning in a paper or an assignment written, in whole or in part, by someone else;

- Copying from books, magazines, or other sources, including Internet or other electronic databases like ProQuest and InfoTrac, or paraphrasing ideas from such sources without acknowledging them;

- Submitting an essay for one course to a second course without having sought prior permission from your instructor; 


\section{Issues in Information Systems}

Volume 13, Issue 2, pp. 138-145, 2012

- Giving a speech and using information from books, magazines, or other sources or paraphrasing ideas from sources without acknowledging them;

- Knowingly assisting others in the dishonest use of course materials such as papers, lab data, reports and/or electronic files to be used by another student as that student's own work.

The academic policy of the university (also included in each syllabus) sets forth some guidelines for punishment of those guilty of plagiarism, but basically it is left to the instructor to decide the penalties. Of those surveyed, 57\% thought the offender should receive an $\mathrm{F}$ for the assignment, while only $19 \%$ felt that the offender should fail the entire course. Clearly the CIS students surveyed did not consider cheating worthy of a failing course grade. Even though the students reported that they are aware of the policy (92\%) and their instructor included it in their syllabus $(97 \%)$, it may be that they do not consider copying of code as a very serious offense.

\section{PLAGIARISM CONCERNS IN THE IS/IT/CIS COURSE SYLLABUS}

Some may see Syllabi as both contracts and learning tools [18]. One purpose of a syllabus is to convey rules and regulations [9]. Many faculty view it as a learning tool in that it provides the student with an outline of the topics and required work for the course.

A study was conducted by Davis to explore and compare student and faculty expectations for the course syllabi [6]. Students in this study felt that the syllabus was more of a "nuts and bolts" about the course and not a learning tool for the course. They seemed most interested in the grading policies, professor contact information and assignment deadlines. Adult students were most interested in what will get them the best grade in a most efficient manner [13]. These students may not be concerned with plagiarism statements.

Some Professors ask their students to sign the syllabus, thereby confirming that the students agree to adhere to all requirements within. Professor Hatch at the Colorado State University requires his students to sign that they have read and accept the terms of the course syllabus [11]. Other Professors require their students to take a quiz on the syllabus. Raymark, for example, developed a syllabus quiz to enhance understanding of course policies and procedures. When the results from the syllabus quiz were analyzed, it was interesting to note that only $60 \%$ of the students returned the quiz (even though they were told they would get extra credit for completing it) [20].

But is the student really paying attention to the plagiarism section of the syllabus? Does the Professor need to be more emphatic about the policy?

Computer and Information Systems course syllabi from the authors' Institution were reviewed to determine what is included concerning plagiarism and/or cheating. All instructors included the University policy on cheating in their syllabus (this is required by the University). Additional results are as follows:

- Those specifically stating that copying from the Internet is cheating - $22 \%$

- Those stating that copying of computer code is cheating - 50\%

- Those stating what the penalty for cheating is - $20 \%$

Almost all of the syllabi reviewed did not have the instructor's plagiarism policies towards the beginning of the document. This raises the question: should plagiarism policies be placed at the beginning of syllabi in order to make the policies more effective?

\section{IMPLICATIONS FOR CHEATING}

IS/IT/CS students who are planning to work in or are already working in industry may be receiving a mixedmessage concerning cheating. In industry, teamwork and collaboration on work tasks is encouraged as a means to improve efficiency and reduce costs. In a 2010 interview, David Foote, CEO of Foote Partners, stated "In the real 


\section{Issues in Information Systems}

Volume 13, Issue 2, pp. 138-145, 2012

world, people write [software] code in teams where they are given pieces of a project to work on. The academic world should be mapping onto the real world . . . they shouldn't be handing out assignments where people are coding on their own" [14]. The overarching dilemma, therefore, is what constitutes "collaboration" and what constitutes cheating? Certainly, business organizations do not want to advocate any employee behavior that might place the organization at legal or financial risk. Recent disasters such as Enron, Worldcom, and Tyco Corporation have underscored the tremendous dangers of deceit and dishonesty in the workplace [8]. Even more alarming, numerous studies have shown that the tendency to be dishonest at work by an employee is highly correlated to that individual's tendency to cheat in college [17].

Pervasive cheating by students can also have a direct effect on the university itself. Being tolerant of cheating can harm the reputation and perceived quality of an academic institution. This tarnished reputation can lead to a diminished regard for the institution's programs, and ultimately, for the institution's graduates [8].

\section{CONCLUSION - STRATEGIES TO DETER CHEATING AMOUNG IS/IT/CIS STUDENTS}

At first glance, it may seem that increasing the enforcement and penalties for cheating and plagiarism is the way to deter future infractions. Some studies, however, attest that such approaches might actually incite more cheating among students. Rettinger and Kramer, for example, note that stricter penalties tend to create "neutralizing" attitudes and stronger extrinsic motivation among students. According to these authors, "Students perceive these measures as indications of mistrust and often rebel as a result" [21].

As previously stated, Intrinsic motivation (i.e., mastery) tends to encourage less cheating. Therefore, IS/IT/CS faculty should use assignments that encourage the students to "master" the related concepts. For example, Georgia Tech allows and even encourages students to collaborate on software coding assignments. However, as part of their assignment grade, each student must give an oral demonstration of how their software works; if the student cannot explain his/her own code, the student fails the assignment [14]. In another study, an instructor employed a similar technique using the final examination. In this approach, the final examination for the course is used to ask the student questions about his/her specific programming code [3].

Other authors have suggested using a Social Norms Marketing approach to deter cheating. In this approach, campaigns are organized to show students that cheating is not a "normal" or "typical" behavior that is commonly practiced by their peers. This approach accomplishes the opposite of "neutralizing" by convincing students that "everyone else is NOT doing it." Social Norms Marketing, however, typically involves a concerted, and widespread effort by the entire university [21].

Regardless of what techniques are used by the instructor, the course syllabus should provide specific guidelines about plagiarism. In addition, the section of the syllabus that deals with plagiarism should be more prominent and towards the beginning. This section should be thoroughly discussed on the first day of class and revisited throughout the semester.

A final suggestion, employed by authors of the current paper, is to require "interim" or "draft" assignments from students. Using this approach, an instructor would require the student to submit parts (or drafts) of an assignment at periodic intervals until the final assignment is due. With this approach, a student is forced to work on an assignment "piece-by-piece." By "modularizing" the assignment, the student is less likely to procrastinate (as students typically do) until the night before the final assignment is due. If the student has more time to complete the assignment, he/she is less likely to plagiarize code from the Internet or from a classmate.

This last suggestion resulted from a recent personal experience by one of the authors in an undergraduate Computer and Information Systems (CIS) course. An undergraduate student was caught plagiarizing content off of the professor's own lecture slides (which were posted on the professor's faculty website). The student blatantly copied whole paragraphs of content from the slides and pasted the content into homework assignments. When asked why 


\section{Issues in Information Systems}

Volume 13, Issue 2, pp. 138-145, 2012

he cheated, the student replied "I was pressed for time and I wanted to try to get all the assignments in to have a chance at passing the class."

The above scenario seems to be very typical of college students; especially undergraduate students. Students tend to procrastinate on projects and assignments until the last possible minute. In many occasions, students will even miss the assignment deadline and then try to turn assignments in "late" at the end of the semester for "partial credit." This procrastination creates a high-pressure situation for the student that seems to foster dishonest behavior.

As stated previously, one technique for avoiding the high-pressure scenario described above is to require individual sections or parts of assignments from students throughout the semester. By turning in assignments in "piecemeal" fashion, students are less likely to procrastinate until the night before an assignment is due. If the student is under less pressure to meet an assignment deadline, the student may feel less pressure to copy content or programming code into assignments.

\section{REFERENCES}

1. Alcantara,Chris (March 2012) "University of Florida students caught cheating on computer science projects" Contributing Writer for the Independent Florida Alligator, http://www.alligator.org/news/campus/article_8f6af304-6cc8-11e1-9d89-0019bb2963f4.html

2. Anderman, E. M., Griesinger, T., \& Westerfield, G. (1998). Motivation and cheating during early adolescence. Journal of Educational Psychology, 60, 84-93.Baugh (2007) "Student Success with Java Online vs Java OnGround" Information Systems Education Journal (ISEDJ)

3. Callahan, D. (2004). The cheating culture: Why more Americans are doing wrong to get ahead. Florida, US: Harcourt Books.

4. Cizek, Gregory (1999) "Cheating on Tests"

5. Davis, S., et. al., (March 2009) "Comparison of Syllabi Expectations Between Faculty and Students in a Baccalaureate Nursing Program". Journal of Nursing Education, 48(3).

6. Dweck, C. S. (1988). Motivational processes affecting learning. American Psychologist, 41, 1040-1048.

7. Gulli, C., N. Kohler and M. Patriquin (2007). The university cheating scandal, Maclean's, 120(5), 32-36.

8. Habanek, D.V. (2005). "An examination of the integrity of the syllabus". College Teaching, 53, 62-65

9. http://www.wikihow.com/Cheat-On-a-Test,

10. http://tilt.colostate.edu/tips/tip.cfm?tipid=50

11. http://www.ehow.com/about_6401964_computer-programming-code-ethics.html)

12. Leith, K.P. (2002, August). "Adult learning styles and the college classroom". Paper presented at the 110th annual meeting of the American Psychological Assoc., Chicago, IL.

13. Marsan, C. D. (2010). Why computer science students cheat. Network World, 27(8), 14-15.

14. Moorer, Michael (1998) "Cheating 101: The Benefits and Fundamentals of an Easy A"

15. Murdock, T. B., Miller, A., \& Kohlhardt, J. (2004). Effects of classroom context variables on high school students' judgments of the acceptability and likelihood of cheating. Journal of Educational Psychology, 96(4), 765-777.

16. Nonis, S. and C. Smith (2001). Personal value profiles and ethical business decisions. Journal of Education for Business Ethics, 76(5), 251-256.

17. Parks, J., \& Harris, M.B. (2002). College Teaching, 50, 55-61

18. Pulvers, K., \& Diekhoff, G. M. (1999). The relationship between academic dishonesty and college classroom environment. Research in Higher Education, 40(4), 487-498.

19. Raymark, P.H. \& Connor-Greene, P.A. (2002) "The Syllabus Quiz"

20. Rettinger, D. A., \& Kramer, Y. (2009). Situational and personal causes of student cheating. Research in Higher Education, 50(3), 293-313.

21. Schmidt, S. M. P., Ralph, D. L., \& Richardson, J. F. (2010). Online exams: Beware of cheating. The Business Review, Cambridge, 16(1), 53-59.

22. Simkin, M. G., \& Mcleod, A. (2010). Why do college students cheat? Journal of Business Ethics, 94(3), 441453. 


\section{Issues in Information Systems}

Volume 13, Issue 2, pp. 138-145, 2012

23. Teixeira, A. A., C., \& Rocha, M. F. (2010). Cheating by economics and business undergraduate students: An exploratory international assessment. Higher Education, 59(6), 663-701.

24. Watters, M. P., "Jep" Robertson, P.J., \& Clark, R. K. (2011). Student perceptions of cheating in online business courses. Journal of Instructional Pedagogies, 6(1), 1-14

\section{APPENDIX}

\begin{tabular}{|l|c|c|}
\hline \multicolumn{1}{|c|}{ Question } & yes & no \\
\hline Search Internet for help to write code? & $78 \%$ & $22 \%$ \\
\hline Downloaded code from the Internet? & $33 \%$ & $67 \%$ \\
\hline Download code for assignment? & $17 \%$ & $83 \%$ \\
\hline Downloaded code ok for assignment? & $30 \%$ & $70 \%$ \\
\hline Need to cite downloaded code in assignment? & $70 \%$ & $30 \%$ \\
\hline Helped another student with code? & $81 \%$ & $19 \%$ \\
\hline Asked another student for help? & $77 \%$ & $23 \%$ \\
\hline Given code to another student to review? & $56 \%$ & $44 \%$ \\
\hline Reviewed another student's code? & $62 \%$ & $38 \%$ \\
\hline Worked in group on individual code? & $39 \%$ & $61 \%$ \\
\hline Copy of code from Internet plagiarism? & $52 \%$ & $48 \%$ \\
\hline $\begin{array}{l}\text { Copy of code from another student } \\
\text { plagiarism? }\end{array}$ & $59 \%$ & $41 \%$ \\
\hline Emailed another student during exam? & $4 \%$ & $96 \%$ \\
\hline $\begin{array}{l}\text { Instant message another student during } \\
\text { exam? }\end{array}$ & $6 \%$ & $94 \%$ \\
\hline Used smart phone during exam? & $17 \%$ & $83 \%$ \\
\hline Penalty for cheating...fail the assignment & $57 \%$ & $43 \%$ \\
\hline Penalty for cheating...fail the course & $19 \%$ & $81 \%$ \\
\hline Aware of Plagiarism policy? & $92 \%$ & $8 \%$ \\
\hline Instructor has Plagiarism policy in syllabus? & $97 \%$ & $3 \%$ \\
\hline
\end{tabular}

Table 1. Student Questions and Responses 